OPEN ACCESS

Edited by:

Nour Eissa,

University of Manitoba, Canada

Reviewed by:

Tiziano Verri,

University of Salento, Italy

Mamdouh Yousif Elgendy, National Research Centre (NRC),

Egypt

${ }^{*}$ Correspondence: Attila Karsi

karsi@cvm.msstate.edu

Specialty section:

This article was submitted to

Aquatic Physiology,

a section of the journal

Frontiers in Physiology

Received: 19 October 2017 Accepted: 04 December 2017 Published: 18 December 2017

Citation:

Abdelhamed H, Lawrence ML and Karsi A (2017) The Role of TonB Gene

in Edwardsiella ictaluri Virulence. Front. Physiol. 8:1066. doi: 10.3389/fphys.2017.01066

\section{The Role of TonB Gene in Edwardsiella ictaluri Virulence}

\author{
Hossam Abdelhamed, Mark L. Lawrence and Attila Karsi * \\ Department of Basic Sciences, College of Veterinary Medicine, Mississippi State University, Mississippi State, MS, \\ United States
}

Edwardsiella ictaluri is a Gram-negative facultative intracellular pathogen that causes enteric septicemia in catfish (ESC). Stress factors including poor water quality, poor diet, rough handling, overcrowding, and water temperature fluctuations increase fish susceptibility to ESC. The TonB energy transducing system (TonB-ExbB-ExbD) and TonB-dependent transporters of Gram-negative bacteria support active transport of scarce resources including iron, an essential micronutrient for bacterial virulence. Deletion of the tonB gene attenuates virulence in several pathogenic bacteria. In the current study, the role of TonB (NT01EI_RS07425) in iron acquisition and E. ictaluri virulence were investigated. To accomplish this, the $E$. ictaluri ton $B$ gene was in-frame deleted. Growth kinetics, iron utilization, and virulence of the EistonB mutant were determined. Loss of TonB caused a significant reduction in bacterial growth in iron-depleted medium $(p>0.05)$. The Ei $\Delta$ ton $B$ mutant grew similarly to wild-type $E$. ictaluri when ferric iron was added to the iron-depleted medium. The Ei $\Delta$ tonB mutant was significantly attenuated in catfish compared with the parent strain (21.69 vs. $46.91 \%$ mortality). Catfish surviving infection with Ei $\Delta$ tonB had significant protection against ESC compared with naïve fish (100 vs. $40.47 \%$ survival). These findings indicate that TonB participates in pathogenesis of $\mathrm{ESC}$ and is an important $E$. ictaluri virulence factor.

Keywords: tonB, iron, virulence, ESC, channel catfish

\section{INTRODUCTION}

Enteric septicemia of catfish (ESC) was first detected in the southern United States in 1976, and the disease was described in 1979 (Hawke, 1979). The etiologic agent of ESC is Edwardsiella ictaluri, which is in the family Enterobacteriaceae (Hawke et al., 1981). It is a facultative anaerobe that is motile with peritrichous flagella (Plumb and Sanchez, 1983). In its acute form, ESC causes gastroenteric septicemia, and its chronic form causes meningoencephalitis (Shotts et al., 1986; Newton et al., 1989) in cultured channel catfish (Ictalurus punctatus). Outbreaks of ESC occur during early summer and autumn, and fish are more at risk when water temperatures range from 22 to $28^{\circ} \mathrm{C}$ (Francis-Floyd et al., 1987). Stress and poor management practices increase susceptibility to ESC through alteration of host-defense mechanisms (Hawke and Khoo, 2004; Small and Bilodeau, 2005; Cunningham et al., 2014; Eissa and Wang, 2016).

Being the most prevalent bacterial pathogen of catfish (Wagner et al., 2006), E. ictaluri poses a significant economic threat to the commercial catfish industry (Shoemaker et al., 2009), the most 
significant cultured finfish in the United States. Antimicrobials applied as a feed additive are the most common means to control ESC. However, anorexia is one of the first clinical signs associated with ESC, limiting the effectiveness of antimicrobial-medicated feed. Also, because E. ictaluri can survive in pond mud for an extended period (Plumb and Quinlan, 1986), recurrence of infection is common. Furthermore, antimicrobial treatment may result in emergence of resistant strains (Starliper et al., 1993; Dung et al., 2008).

In Gram-negative bacteria, active transport of nutrients and substrates, including iron, hemin, vitamin B12, carbohydrates, and some transition metal elements are achieved by the TonB complex (TonB-ExbB-ExbD) and TonB-dependent transporters (Schauer et al., 2008; Lim, 2010). The TonB system consists of plasma membrane proteins ExbB-ExbD and periplasmic protein TonB, which provides energy to TonB-dependent receptors to transport substrates across the outer membrane (Liao et al., 2015). The ton $B$ gene is located next to exbB and exbD in the order $e x b B$, exbD, and ton $B$ in some bacterial species, such as Neisseria meniningitidis (Stojiljkovic and Srinivasan, 1997), Neisseria gonorrhoeae (Biswas et al., 1997), Xanthomonas campestris (Wiggerich et al., 1997), Pasteurella haemolytica (Graham and Lo, 1997), and Helicobacter pylori (Tomb et al., 1997). In contrast, the ton $B$ gene of Enterobacteriaceae is not linked to the exbB and exbD genes (Hannavy et al., 1990; Bruske and Heller, 1993; Bruske et al., 1993).

TonB-mediated active transport of nutrients is critical for survival of pathogenic bacteria during infection (Braun, 2001). Mutation of the ton $B$ gene causes attenuation of virulence in several pathogenic bacteria (Jarosik et al., 1994; Seliger et al., 2001; Torres et al., 2001; Bosch et al., 2002; Hsieh et al., 2008). However, there is no information available on the importance of TonB in virulence of E. ictaluri. Therefore, the purpose of the current research was to delete the ton $B$ gene of E. ictaluri and characterize virulence of the resulting mutant (Ei $\Delta \operatorname{ton} B)$ in catfish. This study also elucidates the importance of TonB in iron acquisition, which has not been described previously.

\section{MATERIALS AND METHODS}

\section{Ethics Statement}

Catfish were used according to a protocol approved by the Institutional Animal Care and Use Committee at Mississippi State University.

\section{Bacterial Strains and Growth Conditions}

Escherichia coli C118 $\lambda$ pir (Herrero et al., 1990) was used to clone the in-frame deleted ton $B$ gene $(\Delta$ ton $B)$ into pMEG-375 suicide plasmid ( $s a c R B$ mobRP4 R6K ori $\mathrm{Cm}^{\mathrm{r}} \mathrm{Amp}^{\mathrm{r}}$ ) (Dozois et al., 2003). E. coli SM10 $\lambda$ pir (Simon et al., 1982) was used as the donor strain in conjugation for transfer of the suicide plasmid into wild-type E. ictaluri stain 93-146 (Lawrence et al., 1997). Luria-Bertani (LB) and brain heart infusion (BHI) broth and agar (Difco, Sparks, MD) were used to culture E. coli at $37^{\circ} \mathrm{C}$ and E. ictaluri at $30^{\circ} \mathrm{C}$, respectively. When needed, the following antibiotics and sugars (Sigma-Aldrich, Saint Louis, MN) were added to the culture medium; ampicillin $(100 \mu \mathrm{g} / \mathrm{ml})$, colistin $(12.5 \mu \mathrm{g} / \mathrm{ml})$, sucrose $(5 \%)$, and mannitol $(0.35 \%)$.

\section{In-Frame Deletion of the E. ictaluri tonB Gene}

The complete open reading frame of the ton $B$ gene (locus tag = NT01EI_RS07425) was obtained from the E. ictaluri 93146 genome (GenBank accession: CP001600) (Williams et al., 2012). To delete the ton $B$ gene from E. ictaluri, gene splicing by overlap extension method was used as previously described (Horton et al., 1989). Briefly, the 1,114-bp upstream and 1,130-bp downstream fragments of the E. ictaluri ton $B$ gene were amplified using EitonBF01-EitonBR42 and EitonBF807EitonBR01 primer sets (Table 1), respectively. Fusion of upstream and downstream fragments was accomplished by a second PCR step using EitonBF01-EitonBR01 primers. The purified $\triangle$ tonB deletion fragment was cloned into pMEG-375 at the SacI and $\mathrm{BamHI}$ restriction sites using T4 DNA ligase (Promega, Madison, $\mathrm{WI})$. Then the resulting plasmid $(\mathrm{pEi} \Delta$ tonB) was transferred into SM10 $\lambda$ pir donor strain and mobilized into E. ictaluri by conjugation (Karsi and Lawrence, 2007) to obtain a single crossover strain on BHI agar plates containing ampicillin and colistin. The single crossover strain was streaked on LB agar with $5 \%$ sucrose and $0.35 \%$ mannitol to allow a second crossover to occur. Mutant verification was performed by ampicillin sensitivity to ensure loss of the plasmid and by PCR using the EitonBF01 and EitonBR01 primers to confirm $\Delta$ tonB. Final confirmation was conducted by sequencing the amplified $\triangle$ ton $B$ fragment using the EitonBF01S primer. DNA sequencing was performed by Eurofins (Kentucky, USA).

\section{Growth of El $\Delta$ tonB under Iron-Depleted Conditions}

Growth of E. ictaluri $\delta$ tonB and 93-146 were determined in iron-rich medium (BHI broth) and iron-depleted medium as previously described (Holden et al., 2012). Iron depletion in BHI broth was achieved using $100 \mu \mathrm{M}$ 2'2-dipyridyl (DPD), a ferrous iron chelator (Santander et al., 2012). Growth assays were performed in 24-well plates using a Cytation 5 Cell Imaging Multi-Mode Reader (BioTek, Vermont, USA) at $30^{\circ} \mathrm{C}$, with O.D. readings at $\lambda=600 \mathrm{~nm}$ taken every hour for $24 \mathrm{~h}$. All growth

TABLE 1 | List of primers with restriction enzyme used to construct Ei $\Delta$ tonB.

\begin{tabular}{lll}
\hline Primer & Sequence $\mathbf{5}^{\prime} \mathbf{-} \mathbf{3}^{\mathbf{a}, \mathbf{b}}$ & RE \\
\hline EitonBF01 & AAGAGCTCGTTCAAACGTACCCAACGTGA & Sac1 \\
EitonBR42 & AGCCAGGAAAATTGCTCAG & \\
EitonBF807 & CTGAAGCAATITCCTGGCTGTGACTGTCTAT & \\
& TTCGGATCG & \\
EitonBR01 & AAGGATCCATGGACTGCCGAATGAAACAA & BamH1 \\
EitonBF01S & CCTCTGACAGTTCCCAGTTA & \\
\hline
\end{tabular}

a Bold sequences indicate the restriction enzymes (RE) added to the $5^{\prime}$ end primers. Two adenine nucleotides were added to the $5^{\prime}$ to increase the efficiency of restricting cut.

${ }^{b}$ Underlined sequences are the reverse-complement of the EitonBR42 primer.

The EitonBF01S primer was used in sequencing of the tonB gene amplified from Ei $\Delta$ tonB. 
experiments were repeated twice. Each experiment was run with six replicates.

\section{Iron Utilization of Ei $\Delta$ tonB under Iron-Depleted Condition}

Effects of ferric chloride $\left(\mathrm{FeCl}_{3}\right)$, ferric nitrate $\mathrm{Fe}\left(\mathrm{NO}_{3}\right)_{3}$, and ferrous sulfate $\left(\mathrm{FeSO}_{4}\right)$ (Sigma) on the growth of E. ictaluri $\triangle t o n B$ and 93-146 were determined under iron-depleted conditions as previously described (Khun et al., 1998). To accomplish this, all iron sources were prepared fresh, sterilized through a $0.45 \mu$ filter, and added to BHI broth at a final concentration of $10 \mu \mathrm{M}$. For each iron source, overnight cultures in $\mathrm{BHI}$ were adjusted to $\mathrm{OD}_{600}=1$ before being subcultured at 1:100 into $5 \mathrm{ml} \mathrm{BHI} \mathrm{media} \mathrm{containing} 100 \mu \mathrm{M} \mathrm{2}$ 2-dipyridyl. Absorbance at $\mathrm{OD}_{600}$ was measured after $18 \mathrm{~h}$. All growth experiments were performed twice independently with four replicates.

\section{Assessment of E. ictaluri $\Delta$ tonB Virulence}

Assessment of virulence was conducted as described (Karsi et al., 2009). Briefly, 240 specific pathogen free (SPF) channel catfish $(13.88 \pm 0.27 \mathrm{~cm}$ and $27.77 \pm 1.04 \mathrm{~g})$ were transferred from the SPF fish hatchery at the College of Veterinary Medicine, Mississippi State University to $1240 \mathrm{~L}$ flow-through tanks with aeration (20 fish per tank). Throughout the experiment, fish were kept at $25-28^{\circ} \mathrm{C}$ and fed to satiety using floating catfish feed. Experimental groups included wild-type strain 93-146, Ei $\Delta$ tonB, and a sham control. Each group was assigned to four tanks randomly. After 1 week acclimation, the water level in tanks was lowered to $10 \mathrm{~L}$. Bacterial cultures grown for $18 \mathrm{~h}$ were added to the tanks to provide an infection dose of $\sim 3.32 \times 10^{7}$ $\mathrm{CFU}$ per $\mathrm{ml}$ of water. CFUs were determined by plating serial dilutions on BHI agar. Fish challenge lasted $1 \mathrm{~h}$, and the sham group was exposed to an equal volume of sterile BHI broth. Fish mortalities were recorded daily. The challenge agent was confirmed as cause of death by culturing anterior kidney swabs on BHI agar. After 21 days post-infection, all fish were re-infected with strain 93-146 (3.83 × $10^{7} \mathrm{CFU} / \mathrm{ml}$ water $)$ as described above to evaluate protective immunity. Mortalities were recorded daily, and the mean percent survival for each treatment was calculated.

\section{Statistical Analyses}

In iron source utilization experiments, independent variables were time and iron source, while bacterial density $\left(\mathrm{OD}_{600}\right)$ was the dependent variable. Q-Q Plots and the Shapiro-Wilk normality test were used for checking normality of data. Homogeneity of variances was checked using Levene's-Test. One-way ANOVA or Robust-Test of Equality of Means tables were used to determine the presence of significant differences among means $(p<0.01)$. The arcsine transformed percent mortality data were subjected to ANOVA using PROC GLM in SAS for Windows v9.4 (SAS Institute, Inc., Cary, NC) to assess significance. Dunnett's post-hoc-test was applied to resolve differences between the means of groups. An alpha level of 0.05 was used in all analyses.

\section{RESULTS}

\section{In-Frame Deletion of the $E$. ictaluri $\Delta$ tonB Gene}

Using a double-selection strategy, we deleted 255 amino acids (including Arg-15 to Gln-269) from the 283 amino acid TonB protein, leaving 14 amino acids at both $\mathrm{N}$ - and Cterminals. Ei $\Delta$ tonB construction was confirmed by sequencing the amplified deletion site (Figures 1, 2).

\section{Growth of $E$. ictaluri $\Delta$ ton $B$ under Iron-Depleted Conditions}

To assess the role of TonB in iron acquisition, we compared the ability of Ei $\Delta \operatorname{ton} B$ and wild-type strain 93-146 to grow in standard and iron-depleted BHI broth. Loss of tonB caused a significant reduction in growth in standard $\mathrm{BHI}$ and when iron was limited by the addition 2,2' -dipyridyl (Figure 3 ).

\section{Iron Utilization of $E$. ictaluri $\Delta$ tonB under Iron Depleted Condition}

$E i \Delta \operatorname{ton} B$ was tested for its ability to utilize ferric iron sources in iron-depleted media. There was no significant difference in growth between EistonB and 93-146 in medium containing ferric chloride, ferric nitrate, and ferrous sulfate as a sole iron source (Figure 4).

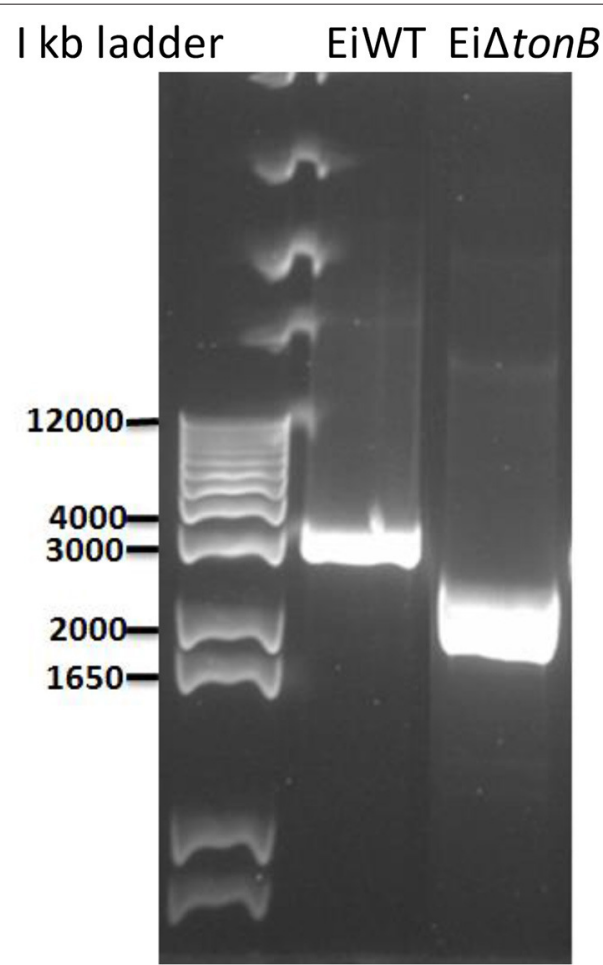

FIGURE 1 | Agarose gel picture showing genotypic confirmation of the Ei $\Delta$ tonB strain by PCR. Lane one is KB Ladder. Lane two is PCR product amplified from wild-type $E$. ictaluri. Lane three is PCR product amplified from genomic DNA of the EistonB strain. 

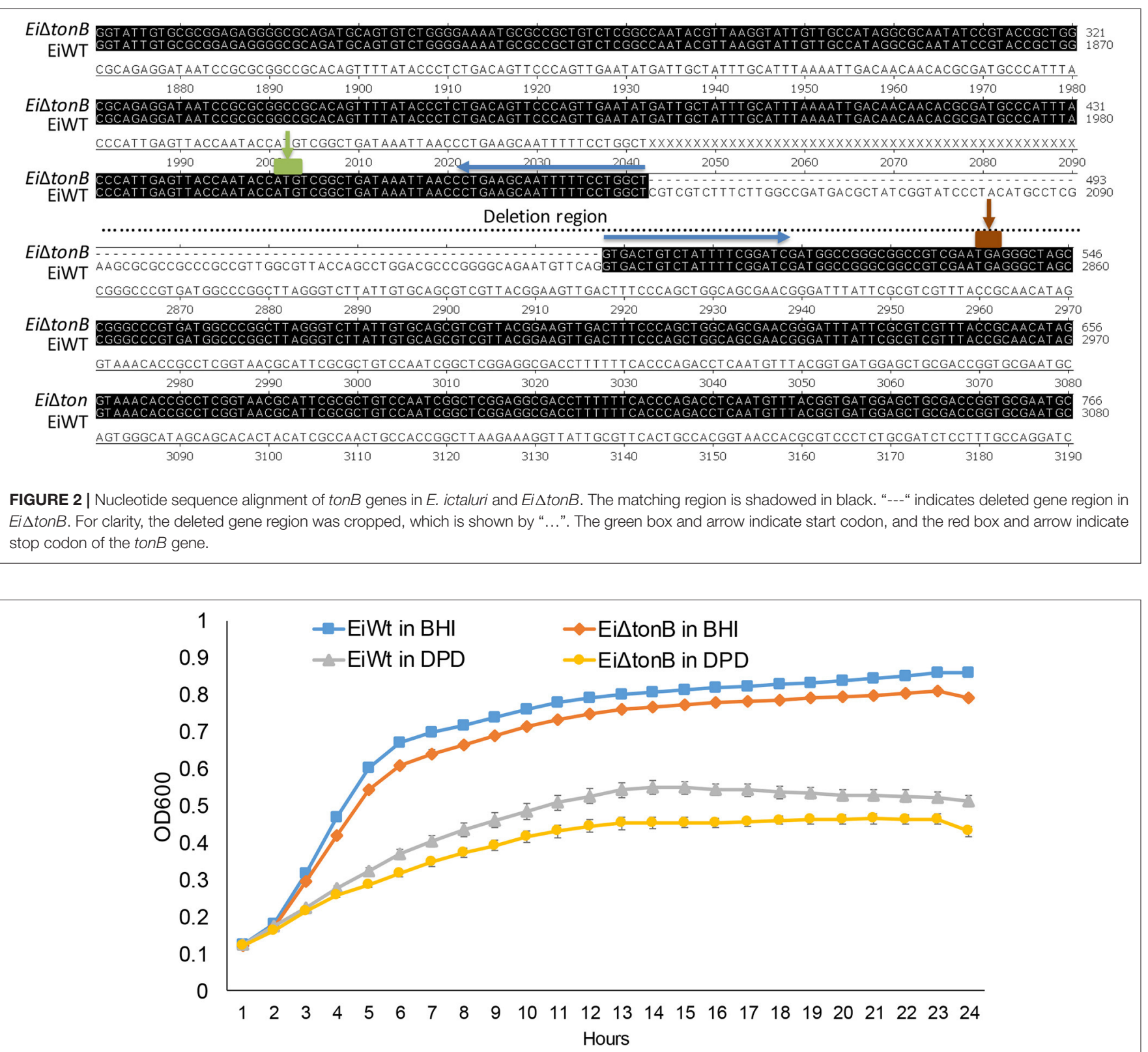

FIGURE 3 | Growth of Ei $\Delta$ tonB and 93-146 in BHI broth and BHI broth supplemented with $100 \mu \mathrm{M}$ 2'2-dipyridyl (DPD). These data represent the mean \pm SE of 12 replicates from two experiments. Standard error bars are shown.

\section{Virulence of $E$. ictaluri $\Delta$ tonB}

Fish infected with $E i \Delta \operatorname{ton} B$ had significantly $(p \leq 0.05)$ lower percent mortalities than fish infected with 93-146 (21.69 vs. $46.91 \%$ mortalities) (Figure 5A). At 21 days post-infection, fish surviving Ei $\Delta$ tonB infection had no mortalities when challenged with wild-type strain 93-146, whereas naïve fish had $40.47 \%$ mean survival (Figure 5B).

\section{DISCUSSION}

TonB mediates transport of iron and vitamin $B_{12}$, as well as nickel, carbohydrates, and other substrates (Noinaj et al., 2010).
In almost all sequenced Gram-negative bacteria, one or more TonB complexes have been identified (Zimbler et al., 2013). The number of TonB proteins is highly variable among bacterial genomes.

The E. ictaluri 93-146 genome harbors four open reading frames (ORFs) annotated as TonB-dependent receptors (NT01EI_RS03180, NT01EI_RS07425, NT01EI_RS08370, and NT01EI_RS16830), which are typically involved in transduction of energy for transport of nutrients across the outer membrane. E. ictaluri TonB has the highest sequence similarity with Edwardsiella piscicida C07-087 TonB (82\% identity), Edwardsiella tarda FL6-60 TonB (81\% identity), and E. tarda 


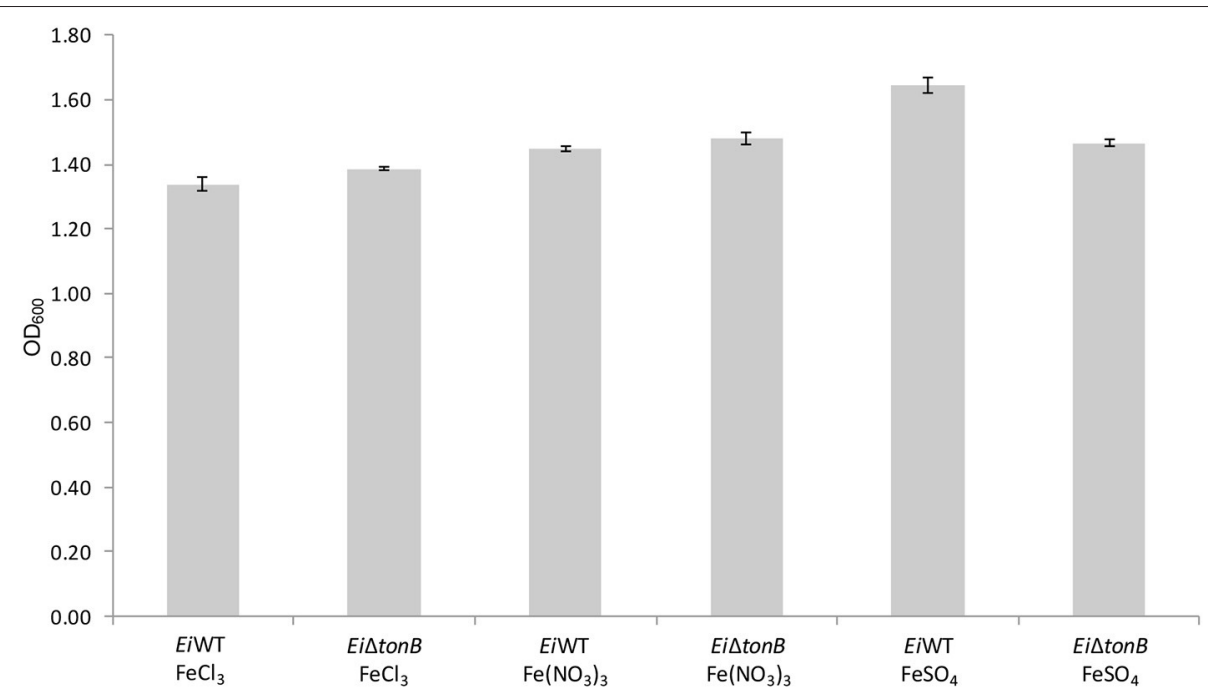

FIGURE 4 | Growth of Ei $\Delta$ tonB and 93-146 in BHI broth containing $100 \mu \mathrm{M}$ DPD and different ferric iron sources. Data represents the mean \pm SE of four replicates.
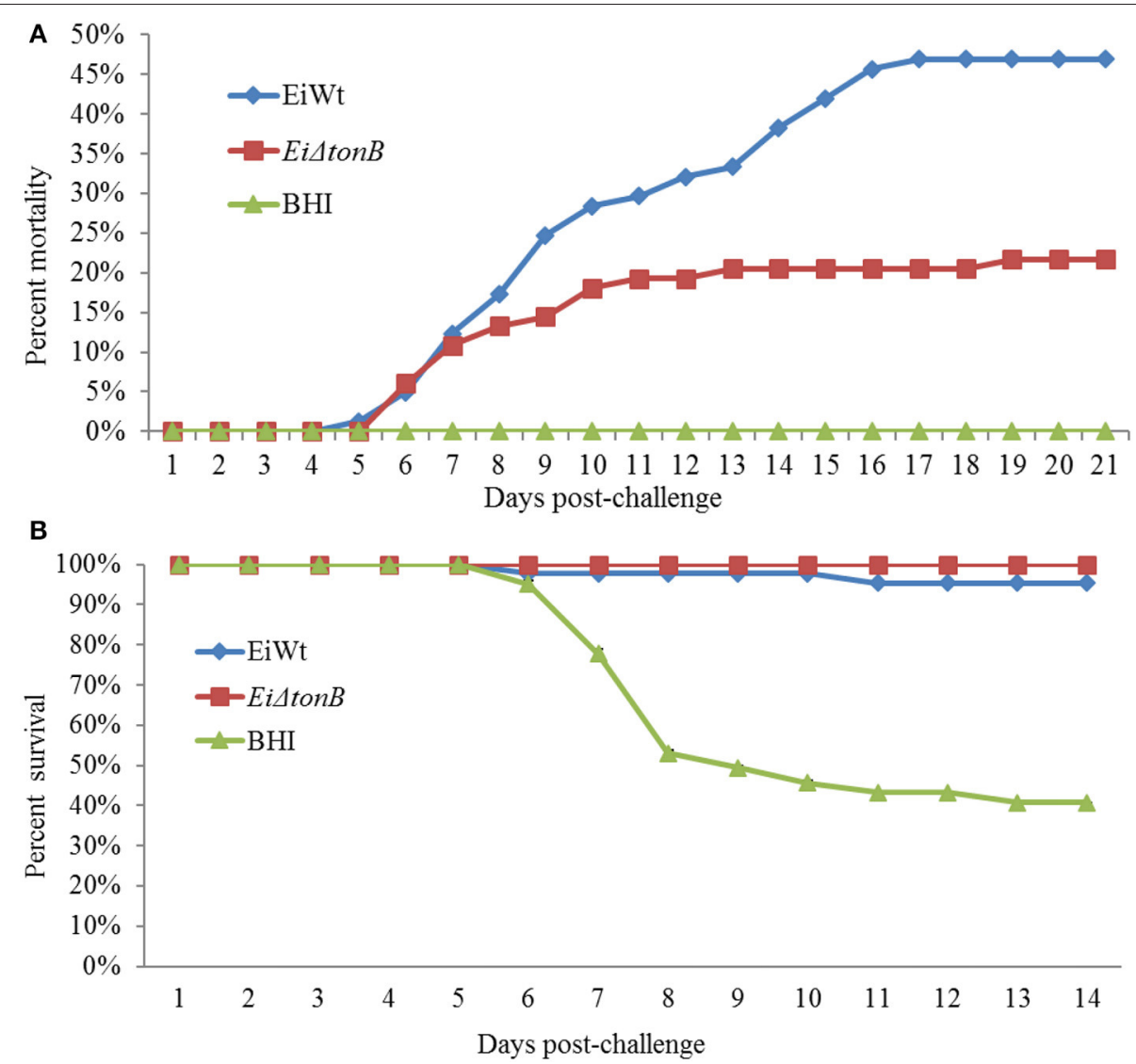

FIGURE 5 | Mean percent mortalities resulting from immersion challenge of Ei $\Delta$ tonB and 93-146 in channel catfish fingerlings (A). Mean percent survival of catfish fingerlings surviving infection with Ei $\Delta \operatorname{ton} B$ and re-challenged with 93-146 at 21 days post-immunization (B).

EIB202 TonB (81\% identity), which is in agreement with species phylogeny. The goal of the current research was to elucidate the role of E. ictaluri TonB in iron acquisition and virulence.
Iron acquisition and utilization play a central role in bacterial growth. The results of in vitro growth assays demonstrated significant decrease in the growth rates in Ei $\Delta$ tonB compared to 
parent strain 93-146 under both iron-replete and iron-depleted conditions. This suggests that TonB contributes to E. ictaluri growth and iron uptake. Interestingly, E. ictaluri encodes multiple iron acquisition systems in its genome, indicating the importance of iron uptake and suggesting it is needed during infection. Similar to our findings, mutation of the TonB protein in the fish pathogen Pseudomonas fluorescens resulted in decreased growth in LB medium with or without iron supplementation (Hu et al., 2012).

Our results also showed that addition of ferric iron improves growth of both Ei $\Delta$ tonB and wild-type E. ictaluri. In a previous study, E. ictaluri ferric hydroxamate uptake mutant (Ei $\Delta f h u C)$ was able to grow using various iron sources (Abdelhamed et al., 2013). Multiple TonB systems have been identified in several pathogenic bacteria such as Vibrio cholera, Vibrio anguillarum, Actinobacillus pleuropneumoniae, and P. areuginosa (Stork et al., 2004). However, not all TonB systems are essential for virulence. For example, in $V$. anguillarum, only tonB2 is essential for the transport of ferric anguibactin and virulence; a ton $B 1$ mutant is fully virulent (Occhino et al., 1998).

Lack of iron leads to significant stress for bacterial pathogens and is considered a signal that leads to changes in virulence gene expression (Massé and Arguin, 2005). In the gastric environment of catfish, E. ictaluri encounters iron starvation stress during the initial phase of infection. Our group identified E. ictaluri proteins that have increased abundance in ironrestricted conditions (Dumpala et al., 2015). In the present study, catfish experiments demonstrated a 2.16-fold reduction in $E i \Delta$ ton B virulence compared with wild-type E. ictaluri. Similarly, $P$. fluorescens mutants defective in the TonB-dependent outer membrane receptor (TDRs) tdr1, tdr2, and tdr3, which had 26.7, 22.3 , and $24.5 \%$ mean percent mortalities, respectively, compared with $70 \%$ mortality caused by the parent strain in a turbot (Seophthalmus maximus) model fish (Zhang et al., 2014).

However, it is possible that the function of TonB in E. ictaluri virulence may be distinct from its role in iron acquisition. There is substantial evidence that TonB function is not restricted to iron uptake. E. ictaluri TonB could be involved in transport of other substrates or the expression of yet-unidentified virulence factors in the host. The E. ictaluri genome does not have exbB and exbD genes, suggesting that E. ictaluri does not utilize the ExbB and

\section{REFERENCES}

Abdelhamed, H., Lu, J., Lawrence, M. L., and Karsi, A. (2016). Involvement of tolQ and tolR genes in Edwardsiella ictaluri virulence. Microb. Pathogen. 100, 90-94. doi: 10.1016/j.micpath.2016.09.011

Abdelhamed, H., Lu, J., Shaheen, A., Abbass, A., Lawrence, M. L., and Karsi, A. (2013). Construction and evaluation of an Edwardsiella ictaluri fhuC mutant. Vet. Microbiol. 162, 858-865. doi: 10.1016/j.vetmic.2012.11.006

Biswas, G. D., Anderson, J. E., and Sparling, P. F. (1997). Cloning and functional characterization of Neisseria gonorrhoeae tonB, exbB and exbD genes. Mol. Microbiol. 24, 169-179. doi: 10.1046/j.1365-2958.1997.3421692.x

Bosch, M., Garrido, E., Llagostera, M., Pérez de Rozas, A. M., Badiola, I., and Barbé, J. (2002). Pasteurella multocida exbB, exbD and tonB genes are physically linked but independently transcribed. FEMS Microbiol. Lett. 210, 201-208. doi: 10.1111/j.1574-6968.2002.tb11181.x
ExbD proteins from the TonB-ExbB-ExbD complex. Moreover, deletion of tolQ and tolR genes, which are $\operatorname{exbB}$ and $\operatorname{exbD}$ homologs, does not affect E. ictaluri iron utilization (Abdelhamed et al., 2016). In Shigella dysenteriae, TonB is required for virulence and growth in the intracellular environment, but it is not required for intracellular iron acquisition (Reeves et al., 2000). Therefore, it is possible that E. ictaluri TonB may be required in vivo for something other than iron transport.

Catfish surviving infection by immersion with $E i \Delta$ tonB were completely protected against subsequent infection by the virulent parent strain, indicating that $E i \Delta \operatorname{ton} B$ stimulated a protective immune response. Ei $\Delta \operatorname{ton} B$ is not safe to be considered a live attenuated vaccine candidate, but our results demonstrate that deletion of TonB causes attenuation without affecting protective immunogenicity. Therefore, it could be a viable gene to use in combination with other gene deletion(s) to develop a live attenuated vaccine.

In conclusion, our experiments showed that TonB participates in virulence of E. ictaluri and contributes to optimal host infection. To our knowledge, this study is the first to describe the contribution of TonB to E. ictaluri virulence. Further work is required to determine which iron transport system or combinations of systems are used to acquire iron during E. ictaluri infection.

\section{AUTHOR CONTRIBUTIONS}

$\mathrm{HA}, \mathrm{ML}$, and $\mathrm{AK}$ planned the experiments. $\mathrm{HA}$ and $\mathrm{AK}$ performed the experiments and analyzed the data. HA, ML, and AK wrote the manuscript.

\section{ACKNOWLEDGMENTS}

This project was supported by Agriculture and Food Research Initiative competitive grant no. 2014-70007-22359 from the USDA National Institute of Food and Agriculture. The authors thank the Laboratory Animal Resources and Care (LARAC) at the College of Veterinary Medicine for providing the SPF catfish. We thank Dr. Robert Wills for his assistance with statistical analyses, and John Harkness and Michelle Banes for proofreading the manuscript.
Braun, V. (2001). Iron uptake mechanisms and their regulation in pathogenic bacteria. Int. J. Med. Microbiol. 291, 67-79. doi: 10.1078/1438-4221-00103

Bruske, A. K., Anton, M., and Heller, K. J. (1993). Cloning and sequencing of the Klebsiella pneumoniae tonB gene and characterization of Escherichia coli-K. pneumoniae TonB hybrid proteins. Gene 131, 9-16. doi: 10.1016/0378-1119(93)90663-N

Bruske, A. K., and Heller, K. J. (1993). Molecular characterization of the Enterobacter aerogenes tonB gene: identification of a novel type of tonB box suppressor mutant. J. Bacteriol. 175, 6158-6168. doi: 10.1128/jb.175.19.6158-6168.1993

Cunningham, F. L., Jack, S. W., Hardin, D., and Wills, R. W. (2014). Risk factors associated with enteric septicemia of catfish on Mississippi commercial catfish farms. J. Aquat. Anim. Health. 26, 84-90. doi: 10.1080/08997659.2014.886635

Dozois, C. M., Daigle, F., and Curtiss, R. III (2003). Identification of pathogen-specific and conserved genes expressed in vivo by an avian 
pathogenic Escherichia coli strain. Proc. Natl. Acad. Sci. U.S.A. 100, 247-252. doi: 10.1073/pnas.232686799

Dumpala, P. R., Peterson, B. C., Lawrence, M. L., and Karsi, A. (2015). Identification of differentially abundant proteins of Edwardsiella ictaluri during iron restriction. PLoS ONE 10:e0132504. doi: 10.1371/journal.pone.0132504

Dung, T. T., Haesebrouck, F., Tuan, N. A., Sorgeloos, P., Baele, M., and Decostere, A. (2008). Antimicrobial susceptibility pattern of Edwardsiella ictaluri Isolates from natural outbreaks of bacillary necrosis of Pangasianodon hypophthalmus in Vietnam. Microb. Drug Resist. 14, 311-316. doi: 10.1089/mdr.2008.0848

Eissa, N., and Wang, H.-P. (2016). Transcriptional stress responses to environmental and husbandry stressors in aquaculture species. Rev. Aquacult. 8, 61-88. doi: 10.1111/raq.12081

Francis-Floyd, R., Beleau, M. H., Waterstrat, P. R., and Bowser, P. R. (1987). Effect of water temperature on the clinical outcome of infection with Edwardsiella ictaluri in channel catfish. J. Am. Vet. Med. Assoc. 191, 1413-1416.

Graham, M. R., and Lo, R. Y. (1997). Cloning and characterization of the exbB-exbD-tonB locus of Pasteurella haemolytica A1. Gene 186, 201-205. doi: 10.1016/S0378-1119(96)00703-2

Hannavy, K., Barr, G. C., Dorman, C. J., Adamson, J., Mazengera, L. R., Gallagher, M. P., et al. (1990). TonB protein of Salmonella typhimurium. A model for signal transduction between membranes. J. Mol. Biol. 216, 897-910. doi: 10.1016/S0022-2836(99)80009-6

Hawke, J. P. (1979). A bacterium associated with pond cultured channel catfish, Ictalurus punctatus. J. Fish. Res. Board Can. 36, 1508-1512. doi: 10.1139/f79-219

Hawke, J. P., and Khoo, L. H. (2004). "Infectious diseases," in Biology and Culture of Channel Catfish, eds C. S. Tucker and J. A. Hargreaves (Amsterdam: Elsevier), 387-443.

Hawke, J. P., McWhorter, A. C., Steigerwalt, A. G., and Brenner, D. J. (1981). Edwardsiella ictaluri sp. nov., the causative agent of enteric septicemia of catfish. Int. J. System. Bacteriol. 31, 396-400. doi: 10.1099/00207713-31-4-396

Herrero, M., de Lorenzo, V., and Timmis, K. N. (1990). Transposon vectors containing non-antibiotic resistance selection markers for cloning and stable chromosomal insertion of foreign genes in gram-negative bacteria. J. Bacteriol. 172, 6557-6567. doi: 10.1128/jb.172.11.6557-6567.1990

Holden, K. M., Browning, G. F., Noormohammadi, A. H., Markham, P. F., and Marenda, M. S. (2012). TonB is essential for virulence in avian pathogenic Escherichia coli. Comp. Immunol. Microbiol. Infect. Dis. 35, 129-138. doi: 10.1016/j.cimid.2011.12.004

Horton, R. M., Hunt, H. D., Ho, S. N., Pullen, J. K., and Pease, L. R. (1989). Engineering hybrid genes without the use of restriction enzymes: gene splicing by overlap extension. Gene 77, 61-68. doi: 10.1016/0378-1119(89)90359-4

Hsieh, P. F., Lin, T. L., Lee, C. Z., Tsai, S. F., and Wang, J. T. (2008). Serum-induced iron-acquisition systems and TonB contribute to virulence in Klebsiella pneumoniae causing primary pyogenic liver abscess. J. Infect. Dis. 197, 1717-1727. doi: $10.1086 / 588383$

Hu, Y. H., Dang, W., and Sun, L. (2012). A TonB-dependent outer membrane receptor of Pseudomonas fluorescens: virulence and vaccine potential. Arch. Microbiol. 194, 795-802. doi: 10.1007/s00203-012-0812-3

Jarosik, G. P., Sanders, J. D., Cope, L. D., Muller-Eberhard, U., and Hansen, E. J. (1994). A functional tonB gene is required for both utilization of heme and virulence expression by Haemophilus influenzae type b. Infect. Immun. 62, 2470-2477.

Karsi, A., Gülsoy, N., Corb, E., Dumpala, P. R., and Lawrence, M. L. (2009). High-throughput bioluminescence-based mutant screening strategy for identification of bacterial virulence genes. Appl. Environ. Microbiol. 75, 2166-2175. doi: 10.1128/AEM.02449-08

Karsi, A., and Lawrence, M. L. (2007). Broad host range fluorescence and bioluminescence expression vectors for Gram-negative bacteria. Plasmid 57, 286-295. doi: 10.1016/j.plasmid.2006.11.002

Khun, H. H., Kirby, S. D., and Lee, B. C. (1998). A Neisseria meningitidis fbpABC mutant is incapable of using nonheme iron for growth. Infect. Immun. 66, $2330-2336$.

Lawrence, M. L., Cooper, R. K., and Thune, R. L. (1997). Attenuation, persistence, and vaccine potential of an Edwardsiella ictaluri purA mutant. Infect. Immun. $65,4642-4651$.

Liao, H., Liu, M., and Cheng, A. (2015). [Structural features and functional mechanism of TonB in some Gram-negative bacteria-a review]. Acta Microbiol. Sin. 55, 529-536.
Lim, B. L. (2010). TonB-dependent receptors in nitrogen-fixing nodulating bacteria. Microbes Environ. 25, 67-74. doi: 10.1264/jsme2.ME10102

Massé, E., and Arguin, M. (2005). Ironing out the problem: new mechanisms of iron homeostasis. Trends Biochem. Sci. 30, 462-468. doi: 10.1016/j.tibs.2005.06.005

Newton, J. C., Wolfe, L. G., Grizzle, J. M., and Plumb, J. A. (1989). Pathology of experimental enteric septicaemia in channel catfish, Ictalurus punctatus (Rafinesque), following immersion-exposure to Edwardsiella ictaluri. J. Fish Dis. 12, 335-347. doi: 10.1111/j.1365-2761.1989.tb00322.x

Noinaj, N., Guillier, M., Barnard, T. J., and Buchanan, S. K. (2010). TonBdependent transporters: regulation, structure, and function. Annu. Rev. Microbiol. 64, 43-60. doi: 10.1146/annurev.micro.112408.134247

Occhino, D. A., Wyckoff, E. E., Henderson, D. P., Wrona, T. J., and Payne, S. M. (1998). Vibrio cholerae iron transport: haem transport genes are linked to one of two sets of tonB, exbB, exbD genes. Mol. Microbiol. 29, 1493-1507. doi: 10.1046/j.1365-2958.1998.01034.x

Plumb, J. A., and Quinlan, E. E. (1986). Survival of Edwardsleila ictaluri in pond water and bottom mud. Progr. Fish Cult. 48, 212-214. doi: 10.1577/1548-8640(1986)48\&lt;212:SOEIIP\&gt;2.0.CO;2

Plumb, J. A., and Sanchez, D. J. (1983). Susceptibility of five species of fish to Edwardsiella ictaluri. J. Fish. Dis. 6, 261-266. doi: 10.1111/j.1365-2761.1983.tb00075.x

Reeves, S. A., Torres, A. G., and Payne, S. M. (2000). TonB is required for intracellular growth and virulence of Shigella dysenteriae. Infect. Immun. 68, 6329-6336. doi: 10.1128/IAI.68.11.6329-6336.2000

Santander, J., Golden, G., Wanda, S. Y., Curtiss, R. III (2012). Fur-regulated iron uptake system of Edwardsiella ictaluri and its influence on pathogenesis and immunogenicity in the catfish host. Infect. Immun. 80, 2689-2703. doi: 10.1128/IAI.00013-12

Schauer, K., Rodionov, D. A., and de Reuse, H. (2008). New substrates for TonBdependent transport: do we only see the 'tip of the iceberg'? Trends Biochem. Sci. 33, 330-338. doi: 10.1016/j.tibs.2008.04.012

Seliger, S. S., Mey, A. R., Valle, A. M., and Payne, S. M. (2001). The two TonB systems of Vibrio cholerae: redundant and specific functions. Mol. Microbiol. 39, 801-812. doi: 10.1046/j.1365-2958.2001.02273.x

Shoemaker, C. A., Klesius, P. H., Evans, J. J., and Arias, C. R. (2009). Use of modified live vaccines in aquaculture. J. World Aquac. Soc. 40, 573-585. doi: 10.1111/j.1749-7345.2009.00279.x

Shotts, E. B., Blazer, V. S., and Waltman, W. D. (1986). Pathogenesis of experimental Edwardsiella ictaluri infection in channel catfish (Ictalurus punctatus). Can. J. Fish. Aquat. Sci. 43, 36-42. doi: 10.1139/f86-005

Simon, R., Priefer, U., and Piihler, A. (1982). A broad host range mobilization system for in vivo genetic engineering: transposon mutagenesis in gramnegative bacteria. Biotechnology 1, 784-791. doi: 10.1038/nbt1183-784

Small, B. C., and Bilodeau, A. L. (2005). Effects of cortisol and stress on channel catfish (Ictalurus punctatus) pathogen susceptibility and lysozyme activity following exposure to Edwardsiella ictaluri. Gen. Comparat. Endocrinol. 142, 256-262. doi: 10.1016/j.ygcen.2004.12.004

Starliper, C. E., Cooper, R. K., Shotts, E. B., and Taylor, P. W. (1993). Plasmidmediated romet resistance of Edwardsiella ictaluri. J. Aquat. Anim. Health 5 , 1-8. doi: 10.1577/1548-8667(1993)005\&lt;0001:PMRROE\&gt;2.3.CO;2

Stojiljkovic, I., and Srinivasan, N. (1997). Neisseria meningitidis tonB, exbB, and exbD genes: Ton-dependent utilization of protein-bound iron in Neisseriae. J. Bacteriol. 179, 805-812. doi: 10.1128/jb.179.3.805-812.1997

Stork, M., Di Lorenzo, M., Mouriño, S., Osorio, C. R., Lemos, M. L., and Crosa, J. H. (2004). Two tonB systems function in iron transport in Vibrio anguillarum, but only one is essential for virulence. Infect. Immun. 72, 7326-7329. doi: 10.1128/IAI.72.12.7326-7329.2004

Tomb, J. F., White, O., Kerlavage, A. R., Clayton, R. A., Sutton, G. G., Fleischmann, R. D., et al. (1997). The complete genome sequence of the gastric pathogen Helicobacter pylori. Nature 388, 539-547. doi: 10.1038/41483

Torres, A. G., Redford, P., Welch, R. A., and Payne, S. M. (2001). TonB-dependent systems of uropathogenic Escherichia coli: aerobactin and heme transport and TonB are required for virulence in the mouse. Infect. Immun. 69, 6179-6185. doi: 10.1128/IAI.69.10.6179-6185.2001

Wagner, B. A., Wise, D. J., Khoo, L. H., and Terhune, J. S. (2006). The epidemiology of bacterial diseases in food-size channel catfish. J. Aquat. Anim. Health 18, 263-272. doi: 10.1577/1548-8667(2002)014<0263:TEOBDI >2.0.CO;2 
Wiggerich, H. G., Klauke, B., Köplin, R., Priefer, U. B., and Puhler, A. (1997). Unusual structure of the tonB-exb DNA region of Xanthomonas campestris pv. campestris: tonB, exbB, and exbD1 are essential for ferric iron uptake, but exbD2 is not. J. Bacteriol. 179, 7103-7110. doi: 10.1128/jb.179.22.7103-7110.1997

Williams, M. L., Gillaspy, A. F., Dyer, D. W., Thune, R. L., Waldbieser, G. C., Schuster, S. C., et al. (2012). Genome Sequence of Edwardsiella ictaluri 93-146, a strain associated with a natural channel catfish outbreak of enteric septicemia of catfish. J. Bacteriol. 194, 740-741. doi: 10.1128/JB.065 $22-11$

Zhang, S. R., Zhang, L., and Sun, L. (2014). Identification and analysis of three virulence-associated TonB-dependent outer membrane receptors of Pseudomonas fluorescens. Dis. Aquat. Organ. 110, 181-191. doi: 10.3354/dao02771
Zimbler, D. L., Arivett, B. A., Beckett, A. C., Menke, S. M., and Actis, L. A. (2013). Functional features of TonB energy transduction systems of Acinetobacter baumannii. Infect. Immun. 81, 3382-3394. doi: 10.1128/IAI.00540-13

Conflict of Interest Statement: The authors declare that the research was conducted in the absence of any commercial or financial relationships that could be construed as a potential conflict of interest.

Copyright (c) 2017 Abdelhamed, Lawrence and Karsi. This is an open-access article distributed under the terms of the Creative Commons Attribution License (CC BY).

The use, distribution or reproduction in other forums is permitted, provided the original author(s) or licensor are credited and that the original publication in this journal is cited, in accordance with accepted academic practice. No use, distribution or reproduction is permitted which does not comply with these terms. 